\title{
A Meta Analysis of Natural Gas Consumption
}

\author{
Prabodh Kumar Pradhan \\ Research Scholar, \\ Sri Sri University
}

\author{
Sunil Dhal \\ Associate Professor \\ Sri Sri University
}

\begin{abstract}
Natural Gas is considered to be one of the leading energy sources for India which provide pollution free, flexible to move to our industry. Due to limited Natural Gas resource, it is a challenge to conserve, utilize our resource in an optimal way. For this a number of authors are tried to predict the natural gas consumption in short and long term basis using mathematical and computational Techniques. The objective of the paper is to meta-analysis the papers published related to Natural Gas consumption for the year 2002-2017. This research helps to find out a better and accurate prediction techniques in short and long term basis for prediction of Natural GasConsumption(NGC).
\end{abstract}

\section{Keywords}

NGC.

\section{INTRODUCTION}

Natural gas(NG) is an important energy resources that is becoming more and more popular because of its environmental benefits(lower impact on environmental pollution). All most all developed countries are concerned about the natural gas consumption due to low reserve. Omer Fahrettin Dem, IREL, Selim Zaim, 2011 predicted that china's natural gas consumption will continue to grow and expected to achieve $354.1 \mathrm{bcm}$ by 2020 . Michael Ratner(India), 2017 on his research article, he found that the natural gas portion in India's energy mix is $7 \%$ as it remains small compared to that of the US and other developed countries like Brazil, China. India's target it to double the proportion of natural gas consumption by 2022 . To achieve this goal we would require major upstream, midstream and downstream investments as well as the continued political will to take necessary steps and to decrease reliance on coal and oil. Therefore, demand for this source of energy has increased considerably in recent years. The largest increase in world's primary energy consumption is attributed to N.G as per U.S Energy Information Administration 2016.

It is projected that the Natural Gas consumption as primary energy source will increase to $2040 \mathrm{TCF}$ compared to the recorded consumption $120 \mathrm{TCF}$ in the year 2012-2013. As per British Petroleum(BP) global 2015 NG contributes $23.8 \%$ of the primary energy consumption globally and remains as the main fuel in production of electricity and as a fuel for the industry.
A number of researchers attempted to develop models for the prediction of NGC on daily, weekly, monthly, quarterly and yearly basis. It has reviewed that the computational models were suitable for natural gas consumption for a better input parameters. The model efficiency not only depends upon the algorithm but majorly depends upon the input parameters. Every natural gas distributor is obliged to make a nomination of natural gas by its supplier, which is the amount of gas needed for the future days. There is a certain $\mathrm{regul}$ a t e d tolerance that is allowed. In case the actual consumption exceeds the nominated amount, the distributor must pay a certain penalty. On the other hand, if nominated amount exceed actual consumption, different type of penalty will be charged as well. Since the incorrect nominations lead to $\mathrm{high}$ costs, accurate predictions of natural gas consumption for the following day are very important due to financial reasons.

\section{METHODOLOGY}

For the research purposes, literature overview analysis was conducted using PRQUEST database. The keywords "natural gas consumption”, “ " "prediction of Natural Gas” OR "demand of Natural Gas", "Consumption of Natural Gas", "Prediction models in Natural Gas)", were used for searching articles. The articles were searched within three indexes: Science Citation Index Expanded (SCI-Expanded), Social Science Citation Index (SCI), and Arts and Humanities Citation Index (A\&HCI) for the period of 2002 to 2017.

This search resulted with 276 papers, including article (201), proceedings paper (28) and review (47). After reviewing the title, abstracts and keywords of all found articles, articles that are not related to models for prediction of CNG for residential or commercial use were eliminated. Thereafter, 72 articles remain that met posted criteria. Those papers were analysed according to several criteria: methods used for predictions of $\mathrm{CNG}$, input variables used for modelling, prediction area and prediction horizon.

Similar literature review was conducted by Soldo (2012), who analysed natural gas consumption from the year 1949 to 2010 and Dario Sebalj, Josip Mesarie, Davor Dujak , 2017, he predicted the Natural Gas consumption from the year 20022017 using web of science core collection (WOSCC) database.

As it can be seen in Table 1, in the last three years 34 papers considering natural gas prediction were published, which is more than $55 \%$ of all analysed papers. 
Table-1.Number of published papers per year

\begin{tabular}{|c|c|c|c|}
\hline Year publication & Number & $\%$ & Authors \\
\hline 2004 & 1 & $1.38 \%$ & Gil\&Deferrari. \\
\hline 2005 & 2 & $2.76 \%$ & Aras;Gutierrezetal. \\
\hline 2006 & 2 & $2.76 \%$ & Hillard G. Huntington, DejanIvezić \\
\hline 2007 & 4 & $5.52 \%$ & $\begin{array}{l}\text { Potocnik et al, Hongjie Lu, HongjunYou, Reed P. Timmer, Peter J. Lamb; } \\
\text { Syed Ali Naqi, Syed Jamil Hassan Kazmi, Jeong C. Seong }\end{array}$ \\
\hline 2008 & 2 & $2.76 \%$ & Brabecetal., Nil Aras. \\
\hline 2009 & 3 & $4.14 \%$ & $\begin{array}{l}\text { Tonkovic, Omer Fahrettin Dem` IREL, SelimZaim; Steven R. Vitullo; Ronald } \\
\text { H. Brown; George F. Corliss, Brian M. Marx. }\end{array}$ \\
\hline 2010 & 7 & $9.66 \%$ & $\begin{array}{l}\text { Azadeh.;Forouzanfar.;Ma\&Li; Mustafa Akkurt, Omer F. Demirel, } \\
\text { SelimZaim; Kaynar, OguzYilmaz, IsikDemirkoparan, Ferhan;F. B. } \\
\text { Gouucu;EbrahimKamrani }\end{array}$ \\
\hline 2011 & 7 & $9.66 \%$ & $\begin{array}{l}\text { Kaynar;Saboe;Zia Wadud, Himadri S Dey, Md. AshfanoorKabir, Shahidul I } \\
\text { Khan;OmerFahrettin Dem, IREL, SelimZaim;Junchen Li, Xiucheng Dong, } \\
\text { JianxinShangguan, Mikael Höök; HosseinIranmanesh, MajidAbdollahzade, } \\
\text { ArashMiranian; HosseinIranmanesh, MajidAbdollahzade, ArashMiranian }\end{array}$ \\
\hline 2012 & 7 & $9.66 \%$ & $\begin{array}{l}\text { Demirel.;Olgun, MahbuburRahman, Mohammad Tamim\&LutfarRahman; } \\
\text { Fahim Faisal; Yi-Shian Lee, Lee-Ing Tong; Azari, Ahmad; Shariaty-Niassar, } \\
\text { Mojtaba; Azari, Ahmad; Shariaty-Niassar, Mojtaba; Alborzi, Mahmoud }\end{array}$ \\
\hline 2013 & 4 & $5.52 \%$ & $\begin{array}{l}\text { Taspinar;AhmetGoncu,Mehmet, OguzKarahan, TolgaUmutKuzuba; Hongjie } \\
\text { Lu, Hongjun You; Mohsen Hajabdollahi, MostafaHosseinzadeh, M.M } \\
\text { Ghanadi Arab }\end{array}$ \\
\hline 2014 & 5 & $6.90 \%$ & $\begin{array}{l}\text { Soldo, Nguyen Hoang Viet, JacekMandziuk; Mustafa Akpinar, } \\
\text { NejatYumusak; Krzysztof Nęcka, } \\
\text { MałgorzataTrojanowska:MałgorzataTrojanowska }\end{array}$ \\
\hline 2015 & 11 & $15.18 \%$ & $\begin{array}{l}\text { Azadeh.;Boran;Izadyar;Szoplik;Wu.;Zhuetal.; Wei Zhang, Jun Yang; Halle } \\
\text { Bakhteeyar, Abbas Maleki; JolantaSzoplik; Junwei Miao; Junghwan Jin, } \\
\text { Jinsoo Kim }\end{array}$ \\
\hline 2016 & 10 & $13.8 \%$ & $\begin{array}{l}\text { Akpinar\&Yumusak;Bai\&Li;Baldaccietal.;Zeng\&Li; SergasSergipe Gas S. } \\
\text { A., Aracaju; Mustafa Akpinar, M. Fatih Adak, NejatYumusak; } \\
\text { BeyzanurCayirErvural, Omer FarukBeyca, SelimZaim; Gaurav Bhattacharya; } \\
\text { Hans-Holger , Rogner; MihaKovačič, BožidarŠarler, UrošŽuperl }\end{array}$ \\
\hline 2017 & 8 & $11.04 \%$ & $\begin{array}{l}\text { Akpinar\&Yumusak;Panapakidis\&Dagoumas; Almir; Beserra dos Santos, } \\
\text { Erika Christina Ashton Nunes Chrisman; Xiaoyu Wang, DongkunLuo, Jianye } \\
\text { Liu, Wenhuan Wang, and GuixinJie; Zhenwu Zhang, Xiantao Liu; Michael } \\
\text { Ratner; DublinSanjay Kumar Kar; Tim Boersma, AkosLosz, AsthaUmmat }\end{array}$ \\
\hline Total & 72 & $100.00 \%$ & \\
\hline
\end{tabular}

\section{Overview of prediction of various time horizons}

Consumption of Natural Gas can be predicted over different time horizons starting from annual basis to hourly basis. Different researchers have used different methods for this purpose. Given below is a list of research papers giving the methods used and different time horizons 
Table2: Overview of predictions of natural gas consumption

\begin{tabular}{|c|c|c|c|c|}
\hline Sl. No & Author & Year & Region & Remarks \\
\hline 1 & S. Gil, J Deferrari & 2004 & Argentina & $\begin{array}{l}\text { ANN is used to predict the maximum consumption } \\
\text { in the intermediate range. }\end{array}$ \\
\hline 2 & DejanIvezić & 2006 & Belgrade & $\begin{array}{l}\text { applications are classifications problems, pattern } \\
\text { recognition and functions approximation. }\end{array}$ \\
\hline 3 & $\begin{array}{l}\text { Hongjie Lu, Hongjun } \\
\text { You }\end{array}$ & 2007 & China & $\begin{array}{l}\text { It results in good economic and social benefits in } \\
\text { China. }\end{array}$ \\
\hline 4 & Nil ARAS & 2008 & Turkey & $\begin{array}{l}\text { ANN used as an alternative solution approach to } \\
\text { forecast the future demand of natural gas. }\end{array}$ \\
\hline 5 & $\begin{array}{l}\text { Omer Fahrettin DEM } \\
\text { IREL, } \\
\text { Selim ZAIM, }\end{array}$ & 2011 & Istanbul & $\begin{array}{l}\text { China will be the number one natural gas } \\
\text { consumption country in the Asia pacific region by } \\
2015 \text {. }\end{array}$ \\
\hline 6 & $\begin{array}{l}\text { HosseinIranmanesh } \\
\text { MajidAbdollahzade } \\
\text { ArashMiranian }\end{array}$ & 2011 & Iran & $\begin{array}{l}\text { The optimized model (ANN) which is employed } \\
\text { for prediction of annual natural gas consumption } \\
\text { in Iran and Unites States. }\end{array}$ \\
\hline 7 & $\begin{array}{l}\text { Hongjie Lu } \\
\text { Hongjun You }\end{array}$ & 2013 & Canada & $\begin{array}{l}\text { The practical experimental values \& Natural gas } \\
\text { consumption in China can be accurately estimated } \\
\text { through prediction models }\end{array}$ \\
\hline 8 & $\begin{array}{l}\text { MałgorzataTrojanowsk } \\
\text { a }\end{array}$ & 2014 & Poland & $\begin{array}{l}\text { Predict the daily demand for natural gas by rural } \\
\text { consumers. }\end{array}$ \\
\hline 9 & $\begin{array}{l}\text { Nguyen Hoang Viet } \\
\text { JacekMandziuk }\end{array}$ & 2014 & Poland & $\begin{array}{l}\text { The neural network model is most efficient } \\
\text { techniques and the result is acceptable by the } \\
\text { natural gas company's viewpoints. }\end{array}$ \\
\hline 10 & $\begin{array}{l}\text { Wei Zhang } \\
\text { Jun Yang }\end{array}$ & 2015 & China & $\begin{array}{l}\text { ANN model can be used as an effective tool to } \\
\text { estimate natural gas consumption in different } \\
\text { countries. }\end{array}$ \\
\hline 11 & $\begin{array}{l}\text { Halle Bakhteeyar } \\
\text { Abbas Maleki }\end{array}$ & 2015 & Iran & $\begin{array}{l}\text { A trial-and-error procedure used to identify the } \\
\text { suitable parameters for prediction of natural gas }\end{array}$ \\
\hline 12 & JolantaSzoplik & 2015 & Poland & $\begin{array}{l}\text { Focused to predict gas consumption on any day of } \\
\text { the year and any hour of the day. }\end{array}$ \\
\hline 13 & $\begin{array}{l}\text { Junghwan Jin } \\
\text { Jinsoo Kim }\end{array}$ & 2015 & Korea & $\begin{array}{l}\text { GARCH model is more suitable model than ANN } \\
\text { techniques to forecast the detail components. }\end{array}$ \\
\hline 14 & $\begin{array}{l}\text { SergasSergipe Gas S. } \\
\text { A., Aracaju }\end{array}$ & 2016 & Brazil & $\begin{array}{l}\text { Daily the producer adjusts its production capacity } \\
\text { considering the availability of transportation } \\
\text { pipelines, gas pipelines and demands from } \\
\text { consumers. }\end{array}$ \\
\hline 15 & $\begin{array}{l}\text { Mustafa Akpinar } \\
\text { M. Fatih Adak } \\
\text { NejatYumusak }\end{array}$ & 2016 & Ukraine & $\begin{array}{l}\text { The ANN model with two hidden layer gives better } \\
\text { results in demand forecasting than the other model. }\end{array}$ \\
\hline 16 & $\begin{array}{l}\text { BeyzanurCayirErvural } \\
\text { Omer FarukBeyca } \\
\text { SelimZaim }\end{array}$ & 2016 & Turkey & $\begin{array}{l}\text { Genetic algorithms provide an objective and } \\
\text { effective identification way for parameter } \\
\text { estimation of ARMA method }\end{array}$ \\
\hline 17 & $\begin{array}{ll}\text { Xiaoyu } & \text { Wang, } \\
\text { DongkunLuo, } & \text { Jianye } \\
\text { Liu, Wenhuan } & \text { Wang, } \\
\text { and GuixinJie } & \\
\end{array}$ & 2017 & China & $\begin{array}{l}\text { The results shows China's natural gas } \\
\text { consumption will grow rapidly over the next five } \\
\text { years and reach354.1billion cubic meters (bcm) by } \\
2020\end{array}$ \\
\hline 18 & $\begin{array}{l}\text { Zhenwu Zhang } \\
\text { Xiantao Liu }\end{array}$ & 2017 & China & $\begin{array}{l}\text { the PSO-GBP prediction model improved the mean } \\
\text { absolute deviation and mean absolute percentage } \\
\text { error values by } 0.065 \text { and } 0.03485 \text { and } 6.67944 \text { and } \\
3.62817 \text {, respectively, and increased the calculation } \\
\text { time by } 0.00726 \text { and } 0.00378 \mathrm{~s} \text {. }\end{array}$ \\
\hline 19 & Sanjay Kumar Kar & 2017 & India & $\begin{array}{l}\text { useful to researchers, professionals, and policy } \\
\text { makers working in the area of natural gas and } \\
\text { related fields. }\end{array}$ \\
\hline 20 & Michael Ratner & 2017 & India & $\begin{array}{l}\text { India is targeting to double the proportion of } \\
\text { natural gas consumption by } 2022 \text {. }\end{array}$ \\
\hline
\end{tabular}


Table-2( Natural Gas Prediction Papers in country wise)

\begin{tabular}{|c|c|c|}
\hline & Country & Number of published Papers \\
\hline 1 & Argentina & 02 \\
\hline 2 & China & 11 \\
\hline 3 & Croatia & 03 \\
\hline 4 & Greece & 01 \\
\hline 5 & Iran & 11 \\
\hline 6 & Italy & 01 \\
\hline 7 & Poland & 05 \\
\hline 8 & Slovakia(SLK) & 01 \\
\hline 9 & Slovenia(SLO) & 02 \\
\hline 10 & Spain(SP) & 01 \\
\hline 11 & Turkey(TUK) & 13 \\
\hline 12 & United Kingdom(UK) & 01 \\
\hline 12 & India(IND) & 03 \\
\hline 13 & Bangadesh & 03 \\
\hline 14 & Brazil & 02 \\
\hline 15 & USA & 02 \\
\hline 16 & Istanbul & 01 \\
\hline 17 & Serbia & 01 \\
\hline 18 & Taiwan & 01 \\
\hline 19 & Canada & 01 \\
\hline 20 & Ukraine & 01 \\
\hline 21 & Korea & 01 \\
\hline 22 & Austria & 02 \\
\hline 23 & Pakistan & 01 \\
\hline
\end{tabular}

\section{OVER VIEW OF PREDICTION HORIZONS}

There are several prediction horizons that can be used for prediction of NG consumption. Large numbers of authors were predicting NG consumption on annual level. Out of which I found four authors predicting Natural gas consumption on yearly basis.

Gil\&Deferrari(2004) presented a model to prediction of the annual consumption of NG for the region in Argentina, Zia Wadud, Himadri S Dey, Md. Ashfanoor Kabir, Shahidul I Khan Gutierrez etal.(2011)used the Engineering-economy models for forecasting annual NG consumption in Bangladesh, Halle Bakhteeyar, Abbas Maleki(2015) used a Radial Basis Function Neural Network (RBFNN)\&Particle Swarm Optimization (PSO) to predict the annual NG consumption in Iran, Mustafa Akpinar, M. Fatih Adak \&NejatYumusak (2016) predicted Ukraine gas consumption in 2016 by using hybrid neural network, Olgunetal.(2012)presented a model in order to calculate the annual NG demand for Turkey until year 2030,Boran(2015),Wuetal. (2015) and Zeng\&Li (2016)used grey prediction models to predict annual NG consumption in Turkey and China. Forouzan faretal.(2010) modeled seasonal NG consumption as well as Baldaccietal.(2016).

There are eight papers in which monthly prediction of Natural Gas consumption was reported below. Predicting NG consumption on monthly level was reported by Aras(2005), who forecasted residential consumption using genetic algorithms, Nobuyuki Higashi (2009) who predict the monthly consumption in china, Nguyen Hoang Viet\& Jacek
Mandziuk(2014) who predict the monthly consumption by using BMA model in china, Jolanta Szoplik(2015) who predict monthly consumption in Poland, Azari, Ahmad, Shariaty-Niassar\&Mojtaba(2012) who predict the monthly prediction in Iran,Azadehet al.(2015), who proposed a computer simulation based on hybrid method and ANFIS, Izadyaret al. (2015), who predicted the residential heating demand in Iran, and Akpinar\&Yumusak(2016), who forecasted NG consumption using time series methods.

There are four papers in which weekly prediction of NG consumption was reported. Those are papers writ in by potocnikat al. (2007), who proposed a forecasting model in order to forecast risk estimation, and Kaynaret al. (2011), who used neural network and neuro fuzzy system for prediction of NG consumption on weekly basis. Dejan Ivezić (2006) predicts natural gas consumption on weekly basis by using ANN model in Belgrade, Serbia. Małgorzata Trojanowska(2014) also predict on weekly basis by using Regression model in Poland.

There are many number of authors predicted NG consumption on daily level.

Gil \& Deferrari(2004) proposed a daily prediction mode lin Argentina, Steven R. Vitullo, Ronald H. Brown; George F. Corliss, Brian M. Marx.(2009) proposed a daily prediction model using mathematical model in USA, Ahmet Goncu Mehmet, Oguz Karahan Tolga \& Umut Kuzuba(2013) proposed a daily prediction model using Temperature modeling approach in Istnabul, Azari, Ahmad, ShariatyNiassar \& Mojtaba (2012) proposed a daily prediction model using Neural Network in Iran, and Potocnik authors(2007) presented a forecasting risk based on risk model to estimating the daily forecasting risk. In order to do that, they had to 
create a model for daily prediction $\mathrm{N}$ Gconsumption. Brabecet al.(2008) forecasted a commercial NG consumption in Slovakia, Azadehetal.(2010) predicted short-term NG demand, Demireletal.(2012),Taspinaretal.(2013) and Akpinar \& Yumusak(2017)predicted daily NG consumption in Turkey, Soldoet al.(2014)used solar radiation as an input variable in order to predict daily NG consumption, Zhuet al. (2015)tried to predict NG demand in United Kingdom, Bai \& Li (2016) proposed a structure-calibrated support vector regression(SCSVR) methods to forecast the daily NG consumption, Panapakidis \&Dagoumas(2017) predicted daily natural gas demand.

Tonkovic at al.), who created a prediction model of NG consumption by using neural networks on a regional level on hourly scale for predicting NG consumption, Sabo etal. (2011), who proposed mathematical models of natural gas consumption, and Szoplik (2015), who forecasted NG consumption in Poland using neural network models. Krzysztof Nęcka, Małgorzata \& Trojanowska who created a prediction model by using Regression model on a particular area on hourly basis to predict Natural Gas consumption.

\section{Over view of prediction methods}

Natural gas consumption is predicted by using various predicting techniques and methods or even a combination of several methods. Soldo(2012) discovered that among the first tools for prediction of Consumption of Natural Gas, Gwasthe Hubbert curve model usedin1950s. Since 1960s, when statistical models were developed, various statistical models have been used for predictions of NG consumption. From the late 1970s and 1980s, the artificial neural networks became very popular forecasting tool. Lately, there are new methods used in predictions of NG consumption such as Grey models or genetic algorithms.

There are only seven papers that predicted natural gas consumption on regional level. Gil\& Deferrari (2004) presented the results for the case of Greater Buenos Aires region in Argentina. DejanIvezić. (2006) investigated the prediction of NG consumption in the region of Belgrade, Serbia to predict the Natural Gas consumption using Parameters of ANN are obtained from the historical data using a Levenberg-Marquardt training algorithm.

Nil Aras (2008), Beyzanur Cayir Ervural Omer Faruk Beyca SelimZaim(2016) used genetic algorithm to predict NGC of Turkey city Eskisehir. Istanbul, Omer Fahrettin DEM ` IREL, Selim ZAIM ,proposed neural networks and multivariate time series models to predict Natural Gas consumption for the city of Istanbul. Ahmet Goncu Mehmet, Oguz Karahan \& Tolga Umut Kuzuba $_{s}(2013)$ propose a methodology which combines natural gas demand estimation with a stochastic temperature model. The model demand and temperature processes separately and derive the distribution of natural gas consumption with a conditional temperature. Hossein Iranmanesh, Majid Abdollahzade \& Arash Miranian (2011) predict natural gas consumption using PSO Optimized least squares in Iran. Hongjie Lu \& Hongjun You (2013) predicts NG consumption using the methods Back propagation \& Gray model in Canada. Małgorzata Trojanowska (2014) predict natural gas consumption using the methods Regression model in Poland. Nguyen Hoang Viet \& Jacek Mandziuk (2014) predicts the NG consumption using methods Neural \& Fuzzy Neural network in Poland. Wei Zhang \&Jun Yang (2015) predicts the consumption by using the techniques Bayesian model, averaging model \& linear regression in China. Halle akhteeyar \& Abbas Maleki (2015) using PSO model to predict the NG consumption in Iran. Jolanta Szoplik (2015) \&Junghwan Jin JinsooKim(2015) predict the NG consumption using ANN in Poland \& Korea. Sergas Sergipe Gas S. A., Aracaju (2016) predict the natural gas consumption using Arima model in Brazil. Mustafa Akpinar, M. Fatih Adak \& Nejat Yumusak (2016) predict NG consumption using technique hybrid neural networks in Ukraine. Beyzanur Cayir Ervural , Omer Faruk Beyca \& SelimZaim (2016) predict natural gas consumption using methods Genetic algorithm in Turkey. Xiaoyu Wang, DongkunLuo, Jianye Liu, Wenhuan Wang, and Guixin Jie (2017) predict the NG consumption using methods hybrid MVO-NNGBM model in China. Zhenwu Zhang \& Liu (2017) predict the natural gas consumption using the method PSO \& Gray neural network in China.Sanjay Kumar Kar \& Michael Ratner (2017) predict the natural gas consumption using techniques ANN in India.

Techniques used for prediction of NG in this paper are Neural Network and Adaptive neural network(NNANN) based, Fuzzy Inference System (ANFIS). Programs of Neural Network use iterative process taking given past data to find the connection between given input and output variables and use the model to capture output value for the given input variables.(ZekicSusac at al. 2009).The fuzzy inference system implemented in the framework of adaptive networks(azadeh at al) by using Adaptive network-based fuzzy inference system(ANFIS).This technique posses both learning capability and structured knowledge representation employed in fuzzy inference systems of neural networks. Therefore it is appropriate for time series non linear models.

Authors who used neural networks were Tonvokovicet al. (2009), Kaynaret al. (2011), Demirelet al. (2012), Olgunet al.(2012), Taspinaret al.(2013), Soldoetal.(2014) Izadyaretal(2015) and Szoplik(2015) Tonkovicetal(2009), Taspinaretal.(2013) and Kaynaretal.(2011) trained and tested two neural network algorithms the multi layer perceptron and the radial basis function network with different activation functions. The first mentioned algorithm produced the smallest mean absolute percentage error in all analyzed paper. Taspinaret al. (2013)also compared neural networks algorithms and time series model. In their research, Demirel and co-authors (2012) used multi layer perceptron algorithm for neural network and compared this model with 2 time series models. Olgunetal.(2012) compared neural networks with support vector machines. Taspinaretal.(2013) and Szoplik(2015) also used a multi layer perceptron algorithm in order to predict NG consumption. Soldoet al. (2014) investigated the emphasis of solar radiation on residential NG consumption. Among several different methods, they used neural networks on two different data sets. The data sets are model house band local distribution from company. Extreme learning machine (ELM), as a learning algorithm for feed forward neural network, was used by Izadyaretal.(2015).

An interesting model which is a combination of different techniques such as Wavelet transform, generate algorithm, ANFIS and feed forward neural network was proposed by Panapakidis \& Dagoumas(2017) . This model hybrid computational intelligence model was tested for its robustness by prediction of day ahead natural gas demands.

Another hybrid model consisting of ANFIS and computer simulation was proposed by Azadehetal.(2015) have presented ANFIS based techniques. The ANFIS is was also used by Kaynar etal.(2011) to predict weekly NG consumption in turkey. 
Ma \& Li(2010) predicted NG consumption based on the Grey system model. The same approach was using Boran (2015) grey prediction with rolling mechanism (GPRM), Wuetal. (2015), and Zeng \&Li (2016). According to Kayacanetal. (2010) "Grey models predict the future values of a time series based only on a set of the most recent data depending on the window size of the predictor.

Other commonly used techniques for NG consumption prediction are support vector regression (SVR) and support vector machine (SVM).Olgunet al. (2012) compared neural networks with support vector machines and they concluded that support vector machines had less statistical error for demand estimation of natural gas consumption. Soldoet al. (2014) used several linear and nonlinear models for predictions. The testing errors obtained by nonlinear neural networks and SVR models are slightly higher compared to linear models. Zhuetal.(2015) presented the method that integrated the SVR algorithm with the reconstruction properties of a time series and optimizes the original local predictor by removing false neighbors. A structure-calibrated SVR approach was used byBai\&Li(2016).

Using genetic algorithms Aras(2008)triedto forecast shortterm demand of NG in residences by Genetic programming technique was used by Forouzan faretal.(2010)and Izadyaretal. (2015)as well.

Some authors used mathematical models in order to predict NG consumption. Gil \& Deferrari(2004)developed a model which is able to predict the NG consumption 1 to 5 days in advance with $10 \%$ of uncertainty. Gutierrez et al. (2005) presented a stochastic Gompertz innovation diffusion model while Potocnik(2007)forecasted NG consumption by using their models used in several gas distribution systems. Brabecetal.(2008) developed non linear mixed effects model(NLME), a parametric statistical model which is later compared with two classical time series approaches. Several advanced linear and non linear mathematical models, such as exponential, Gompertz and logistic model, were used by Saboetal. (2011) Forouzanfaretal. (2010) used a method based on the concept of the nonlinear programming with earlier mentioned genetic programming technique. Soldoetal. (2014)compared several linear models such as autoregressive model with exogenous inputs and stepwise regression. Akpinar \& Yumusak (2017)used multiple linear regression(MLR)for prediction of NG consumption.

There are several time series methods used for predicting NG consumption. Kaynar(2011)and Demirel (2012) used auto regressive integrated moving average (ARIMA).Taspinar(2013)also used type of ARIMA model, called SARIMAX, which is seasonal autoregressive integrated moving average model with exogenous inputs. Akpinar \&Yumusak (2016) presented time series decomposition, Holt-Winters exponential smoothing and ARIMA.

Among other methods used for NG consumption predictions can be highlighted Baldaccietal.(2016), who defined two predicting techniques, one based on a nearest neighbor approach and one employing local regression analysis

Table-3 shows a systematic overview of prediction methods used in predicting natural gas consumption by prediction area and prediction horizon.

\begin{tabular}{|c|c|c|c|c|c|c|c|c|c|c|}
\hline \multirow{2}{*}{$\begin{array}{c}\text { Prediction } \\
\text { method }\end{array}$} & \multicolumn{9}{|c|}{ Predictionarea } & \multicolumn{7}{c|}{ Predictionhorizon* $^{*}$} \\
\cline { 2 - 13 } & Country & Region & City & House & Y & S & M & W & D & H \\
\hline Neuralnetwork & 3 & 3 & 4 & 1 & 2 & & 2 & 2 & 3 & 1 \\
\hline ANFIS & 1 & & & & & & & & 1 & \\
\hline Greymodel & 2 & & & & 2 & & & & 1 & \\
\hline SVM/SVR & 2 & & 2 & 1 & & & & & & \\
\hline GenetiAlgoriths & 2 & & 2 & & 2 & & 2 & & & \\
\hline $\begin{array}{c}\text { Mathematicaland } \\
\text { statisticalmodels }\end{array}$ & 2 & 1 & 2 & 1 & 1 & 1 & & 1 & & 1 \\
\hline Timeseries & 1 & 2 & 1 & & & & & 1 & & \\
\hline Hybridmodels & 2 & & & & & & 1 & 1 & 1 & \\
\hline Other & & & 1 & & & & & & & \\
\hline & & & & & & & & & & \\
\hline
\end{tabular}

*Y yearly, $\mathrm{S}$ seasonal, M monthly, $\mathrm{W}$ weekly, D daily ,H hourly

Table-3(prediction area and horizon)

\section{CONCLUSION}

The study was conducted with seventy two number of research articles of Natural Gas prediction for various Countries in different mathematical and scientific methods. It was found that China and other developed countries are focusing this type of study for weekly, monthly and yearly basis. ANN is the most appropriate techniques for the prediction of Natural Gas consumption. The different researchers applied genetic algorithm, feed forward, back propagation \& PSO methods for this prediction. All most all researchers are agreed upon the other popular methods are neuro-fuzzy inference system, genetic algorithms ,time series methods, support vector machines/ regression, Grey system models, mathematical and statistical models or hybrid models based on several methods. Some researches use two or more methods in the same paper. But analysis has shown that for modeling, authors often use past NG consumption data and weather data (mostly temp.)as input variables. Other variables include month, days of the week, wind speed, temperature, humidity \& price number of natural gas subscribers, GDP, inflation rate etc. Speaking of prediction are as, it can be seen that most of the 
papers deal with the predictions on country level. Predictions can be made as well as on regional, city,or even house level.

\section{REFERENCES}

[1] Xiaoyu Wang, Dongkun Luo, Jianye Liu, Wenhuan Wang \& Guixin Jie, Prediction of Natural Gas Consumption in different regions of China using a hybrid MVO-NNGBM model, Volume 2017, Article ID 6045708, 10 pages, Mathematical problems in Engineering, Hindawi.

[2] Dario Sebalj, Josip Mesaric \& Davor Dujak, Predicting Natural Gas Consumption -A Literature Review, 28 ${ }^{\text {th }}$ CECIIS, September, 27-29, 2017, Varazdin, Croatia.

[3] Zhenwu Zhang \& Xiantao Liu, Prediction of long term gas load based on Particle Swarm optimization and Gray neural network models, Advanced in Mechanical Engineering , 2017 Vol 9(7) 1-8,China.

[4] Beyzanur Cayir Ervural, Omer Faruk Beyca\& Selim Zaim, Model estimation of ARMA using genetic algorithms : A case study of forecasting of Natural Gas consumption, $12^{\text {th }}$ International Strategic Management Conference, ISMC 2016, 28-30 October 2016, Antalya, Turkey.

[5] Akpinar , M., \& Yumusak, N. (2016). Year Ahead Demand Forecast of City Natural Gas Using Seasonal Time Series Methods. Energies, 9(9), 727.

[6] Mohsen Hajabdollahi, Mostafa Hosseinzadeh and M.M Ghanadi Arab, Prediction of Long Term Residential Natural Gas Consumption Using ANN, Journal of Applied Mechanical Engineering , Vol-2, Issue-2 , ISSN:4172/2168-9873, 1000120. Iran.

[7] Aras, N. (2008). Forecasting Residential Consumption of Natural Gas Using Genetic Algorithms. Energy Exploration \& Exploitation, 26(4), 241-266.

[8] Bai, Y., \& Li, C. (2016). Daily natural gas consumption forecasting based on a structure-calibrated support vector regression approach. Energy and Buildings, 127(1), 571579 .

[9] BP Global. (2015). Natural gas consumption Retrieved from http://www.bp.com/en/global/corporate/energyeconomics/statistical-review-of -world-energy/naturalgas/natural-gas-consumption.html .

[10] Krzysztof Nęcka, Małgorzata Trojanowska, Short-Term forecasting of Natural Gas demand by Rural Consumers using Regression model, Teka, Commission of Motorization and Energetics in Agriculture-2014, Vol.14, No.4, 93-98. Poland.

[11] Demirel, O., Zaim, S., Caliskan, A., \& Ozuyar, P. (2012). Forecasting natural gas consumption in Istanbul using neural networks and multivariate time series methods. Turkish Journal of Electrical Engineering and Computer Sciences, 20(5), 695-711.
[12] Gil, S., \& Deferrari, J. (2004). Generalized Model of Prediction of Natural Gas consumption. Journal of Energy Resources Technology, 126(2), 90-98.

[13] oldo, B. (2012). Forecasting natural gas consumption. Applied Energy, 92, 26-37.

[14] Wu, L., Liu, S., Chen, H., \& Zhang, N. (2015). Using a Novel Grey System Model to Forecast Natural Gas Consumption in China. Mathematical Problems in Engineering, 2015, 1-7

[15] Zeng, B., \& Li, C. (2016). Forecasting the natural gas demand in China using a self-adapting intelligent grey model. Energy, 112(1), 810-825.

[16] Ma, Y., \& Li, Y. (2010). Analysis of the supply-demand status of China Natural Gas to 2020. Petroleum Science, 7(1), 132-135.

[17] Zhu, L., Li, M., Wu, Q., \& Jiang, L. (2015). Short-term natural gas demand prediction based on support vector regression with false neighbors filtered. Energy, 80, 428-436.

[18] Wu, L., Liu, S., Chen, H., \& Zhang, N. (2015). Using a Novel Grey System Model to Forecast Natural Gas Consumption in China. Mathematical Problems in Engineering, 2015, 1-7.

[19] Forouzanfar, M., Doustmohammadi, A., Menhaj, M., \& Hasanzadeh, S. (2010). Modeling and estimation of the natural gas consumption for residential and commercial sectors in Iran. Applied Energy, 87(1), 268-274.

[20] Wadud, Z, Dey, HS, Kabir, MA et al, Modeling and forecasting Natural Gas demands in Bangladesh. Energy policy, 39(11). 7372-7380. ISSN 0301-4215.

[21] Omer Fahrettin Dem IREL, Selim Zaim, Ahmet Caliskan \& Pinar Ozuyar, Forecasting Natural Gas consumption in Istanbul using Neural Network and Multivariate time series methods. Turkey. Turk J Electrical Engg \& Comp. Sc., Vol-20, No-5, 2012.

[22] Ahmet Goncu, Mehmet Oguz Karahan and Tolga Umut Kuzubas , Forecasting Daily Residential Natural Gas Consumption: A Dynamic temperature modeling approach, April 30, 2013.

[23] Potocnik, P.,Thaler, M., Govekar, E., Grabec, I., Oredos, A., 2007 . Forecasting risks of Natural Gas consumption in Slovenia Energy Policy 35, 4271-4282.

[24] Nguyen Hoang Vietand Jacek Mandziuk, Neural and Fuzzy Neural Networks in Prediction of Natural Gas Consumption . Institute of Fundamental Technological Research,. Polish Academy of Sciences,. Swietokrzyska 21 Str., 00-049 Warsaw, Poland.

[25] MSc Almir Beserra dos Santos \& DSc Erika Christina Ashton Nunes Chrisman, Natural Gas Consumption Overview In Brazil. Brazil. Quest Journals, Journal of Research in Mechanical Engineering, Volume 3, Issue3(2017) pp:24-28. ISSN(online):2321-8185. 